\title{
$W \mathcal{J} R R_{\text {Radiology }}^{\text {Worl out of }}$
}

Submit a Manuscript: http://www.wjgnet.com/esps/

Help Desk: http:/ /www.wjgnet.com/esps/helpdesk.aspx

DOI: $10.4329 /$ wjr.v8.i2.117

World J Radiol 2016 February 28; 8(2): 117-123

ISSN 1949-8470 (online)

(C) 2016 Baishideng Publishing Group Inc. All rights reserved.

\section{Brainstem tegmental lesions in neonates with hypoxic- ischemic encephalopathy: Magnetic resonance diagnosis and clinical outcome}

\author{
Carlo Cosimo Quattrocchi, Giuseppe Fariello, Daniela Longo
}

Carlo Cosimo Quattrocchi, Department of Medicine and Surgery, Università Campus Bio-Medico di Roma, 00128 Rome, Italy

Giuseppe Fariello, Fatebenefratelli S. Pietro Hospital, 00128 Rome, Italy

Daniela Longo, Unit of Neuroradiology, Bambino Gesù Children's Research Hospital IRCCS, 00128 Rome, Italy

Author contributions: Quattrocchi CC conceived and designed the study and wrote the manuscript; Fariello G critically revised the manuscript for important intellectual content; Longo D supervised the study, collected diagnostic images and references and critically revised the manuscript for important intellectual content.

Conflict-of-interest statement: The authors declare no conflict of interest.

Open-Access: This article is an open-access article which was selected by an in-house editor and fully peer-reviewed by external reviewers. It is distributed in accordance with the Creative Commons Attribution Non Commercial (CC BY-NC 4.0) license, which permits others to distribute, remix, adapt, build upon this work non-commercially, and license their derivative works on different terms, provided the original work is properly cited and the use is non-commercial. See: http://creativecommons.org/ licenses/by-nc/4.0/

Correspondence to: Carlo Cosimo Quattrocchi, MD, PhD, Department of Medicine and Surgery, Università Campus BioMedico di Roma, via Alvaro del Portillo, 00128 Rome,

Italy. c.quattrocchi@unicampus.it

Telephone: +39-062-25411708

Received: August 31, 2015

Peer-review started: September 1, 2015

First decision: September 29, 2015

Revised: October 11, 2015

Accepted: December 9, 2015

Article in press: December 11, 2015

Published online: February 28, 2016

\section{Abstract}

Lesions of the brainstem have been reported in the clinical scenarios of hypoxic-ischemic encephalopathy $(\mathrm{HIE})$, although the prevalence of these lesions is probably underestimated. Neuropathologic studies have demonstrated brainstem involvement in severely asphyxiated infants as an indicator of poor outcome. Among survivors to $\mathrm{HIE}$, the most frequent clinical complaints that may be predicted by brainstem lesions include feeding problems, speech, language and communication problems and visual impairments. Clinical series, including vascular and metabolic etiologies, have found selective involvement of the brainstem with the demonstration of symmetric bilateral columnar lesions of the tegmentum. The role of brainstem lesions in HIE is currently a matter of debate, especially when tegmental lesions are present in the absence of supratentorial lesions. Differential diagnosis of tegmental lesions in neonates and infants include congenital metabolic syndromes and drug-related processes. Brainstem injury with the presence of supratentorial lesions is a predictor of poor outcome and high rates of mortality and morbidity. Further investigation will be conducted to identify specific sites of the brainstem that are vulnerable to hypoxic-ischemic and toxic-metabolic insults.

Key words: Magnetic resonance; Asphyxia; Hypoxicischemic encephalopathy; Tegmentum; Neonates; Brainstem

(C) The Author(s) 2016. Published by Baishideng Publishing Group Inc. All rights reserved.

Core tip: Brainstem tegmental lesions in neonates with hypoxico-ischemic encephalopathy: Magnetic resonance diagnosis and clinical outcome.

Quattrocchi CC, Fariello G, Longo D. Brainstem tegmental 
lesions in neonates with hypoxic-ischemic encephalopathy: Magnetic resonance diagnosis and clinical outcome. World $J$ Radiol 2016; 8(2): 117-123 Available from: URL: http://www. wjgnet.com/1949-8470/full/v8/i2/117.htm DOI: http://dx.doi. org/10.4329/wjr.v8.i2.117

\section{HYPOXIC-ISCHEIMIC ENCEPHALOPATHY IN NEONATES}

Neonatal hypoxic-ischemic encephalopathy (HIE) is a pathological pattern secondary to perinatal events that reduce blood flow in the brain of neonates ${ }^{[1]}$. Most cases of encephalopathy in neonates born at term are related to HIE that occurs in utero or during the delivery from different intrapartum conditions ${ }^{[2]}$. Despite strategies of therapeutic hypothermia such as the whole body cooling have been adopted as a standard treatment for HIE and data from the TOBY (Total Body Hypothermia for Neonatal Encephalopathy) trial have demonstrated its efficacy in improving neurologic outcomes at $18 \mathrm{mo}$ and at 6-7 years of age $e^{[3,4]}$, HIE is still an important cause of early mortality or morbidity and adverse neurodevelopmental outcome in children ${ }^{[1]}$.

In pre-term or very low birthweight neonates, periventricular leukomalacia is observed in at least 50\% of the cases $^{[2]}$. In infants born at 32 gestation weeks and above, neonatal and perinatal strokes are expected in about 1 in 4000 live births ${ }^{[5]}$ and encephalopathy is expected in up to 2 per 1000 term live births ${ }^{[6]}$.

Brain magnetic resonance (MR) is able to discriminate normal from pathological patterns in the neonatal brain $^{[7]}$. Three typical MR imaging patterns have been recognized in neonates with HIE: (1) "watershed", involving the cerebral cortex and subcortical white matter especially in the posterior lobes, following a mild to moderate hypotension or a partial hypoxia with prolonged duration; (2) "basal ganglia-thalamus", following an acute short-duration severe hypoxic or profound hypotensive event; and (3) "total brain injury", involving supra- and infra-tentorial areas following a prolonged and severe hypoxic or hypotensive event ${ }^{[8]}$. While peripheral and basal ganglia-thalamus patterns involve supra-tentorial structures exclusively, the total brain injury shows diffuse supra-tentorial involvement that may be associated with damage of the dorsal brainstem and/or the entire cerebral cortex ${ }^{[8,9]}$.

\section{Involvement of the brainstem in HIE and MR diagnosis}

Lesions of the brainstem have been reported at MR imaging in the clinical scenarios of $\mathrm{HIE}^{[10-15]}$, although the prevalence of these lesions is probably underestimated due to the small size of the brainstem, to the need of dedicated MR protocols under sedation in neonates and, probably, to the "satisfaction of search" effect when diffuse supra-tentorial lesions are present in the condition of total brain injury ${ }^{[16,17]}$.

Neuropathologic studies have demonstrated brain- stem involvement in severely asphyxiated infants as an indicator of poor outcome $e^{[18-20]}$. Leech et al ${ }^{[20]}$ reported brainstem injury in $93 \%$ of asphyxiated infants, especially after prolonged insults. Several gray matter nuclei were involved including the substantia nigra, inferior colliculi, inferior olives, the nuclei of cranial nerves III, IV and VI, the superior olive, the vestibular nuclei, and the nuclei of the solitary tract, gracile tracts, cuneate tracts and reticular formation ${ }^{[20]}$. A neuropathologic study in autoptic cases of patients with various developmental disorders including HIE and congenital metabolic errors highlighted the involvement of the central tegmental tract $(\mathrm{CTT})^{[21]}$. CTT is located between the medio-central tegmentum of the pons and dorsomedial part of the medulla oblongata and has been reported to be included in the dentato-rubro-olivary system, also called GuillainMollaret triangle, whose lesions are associated with the inferior olivary nucleus hypertrophic degeneration ${ }^{[22]}$.

The physiopathological mechanisms underlying HIErelated brainstem alterations are currently unknown and debated. From a topographical point of view, selective vulnerability of the tegmentum, territorial vascularization, haemodynamic compensatory mechanisms under hypoxia, metabolic and biochemical mechanisms have been advocated. In fact: (1) the tegmentum of the brainstem represents the watershed area of the vertebrobasilar vascularization between the terminal territories of the paramedian and circumferential branches ${ }^{[15,23]}$ (Figure 1); (2) the dorsal brainstem has higher metabolic demands than the ventral one and could be selectively damaged under hypoxic-ischemic conditions ${ }^{[24]}$; and (3) experimental studies in mammals have shown that blood flow of the brainstem increases after acute hypoxia ${ }^{[25]}$, as opposed to a blood flow reduction in the cerebrum, suggesting a relative protection of the brainstem fetal circulation. In summary, neuropathologic studies in humans and experimental studies lead to consider the brainstem a less vulnerable site to HIE, with the tegmentum being considered at risk only in the context of severe total brain injury ${ }^{[26]}$.

More recent clinical series ${ }^{[14,15,27-29]}$ have reported on neonates with less severe birth asphyxia than previous neuropathology reports and found selective involvement of the brainstem with the demonstration of symmetric columnar bilateral lesions of the brainstem tegmentum, even in the absence of supratentorial lesions in some cases. In neonates with isolated injury of the brainstem tegmentum, MR imaging shows faint hyperintense signal on T2 weighted images that is associated with the clinical pattern of the so-called "dorsal brainstem syndrome". Bilateral and symmetric lesions of the tegmentum are found that involve the dorsal para-central portions on axial planes and the medulla oblongata and caudal pons cranio-caudally, with sparing of the rostral pons and midbrain (Figure 2 ). As it has been speculated, these brainstem sites are supplied by branches of the vertebro-basilar artery with less flow compensation from the anterior circulation, as compared with the midbrain; also fetal risk factors may 

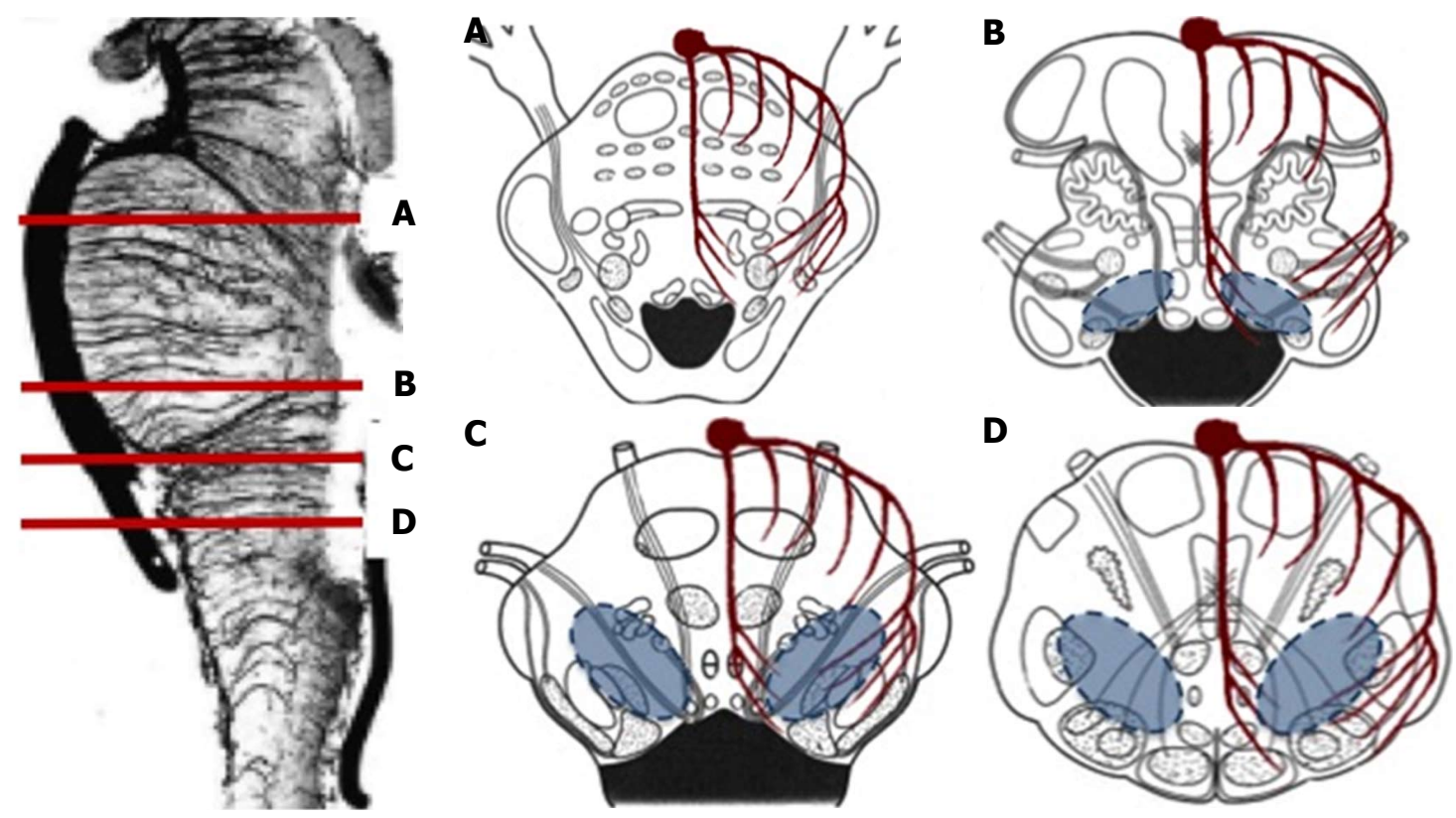

Figure 1 Schematic diagram of the brainstem vasculature. A: Rostral pons; B: Caudal pons; C: Rostral medulla oblongata; D: Caudal medulla oblongata. Basilar artery, the terminal paramedian, short circumferential and long circumferential arteries are depicted. Blue shaded areas represent the tegmental watershed areas that are most frequently affected in neonates and infants with dorsal brainstem syndrome and a history of hypoxic-ischemic encephalopathy.

exist and confer vulnerability to the brainstem, even after not prolonged periods of hypoxia/hypotension ${ }^{[24]}$, such as polyhydramnios or oligoidramnios ${ }^{[15,29]}$. Moreover, unknown genetic susceptibility could be taken into consideration.

Differential diagnosis for this MR pattern includes the columnar-shaped bilateral and symmetric $T 2$ hyperintense signal of the central tegmental tracts that have been reported in various developmental disorders ${ }^{[21,30-32]}$, metabolic diseases including non-ketotic hyperglycinemia $^{[33]}$, mitochondrial diseases ${ }^{[34]}$, perinatal asphy$\mathrm{xia}^{[27]}$, during vigabatrin treatment, and even in control children younger than $25 \mathrm{mo}$ of age ${ }^{[35]}$, with a prevalence of about $5 \%$ in children ranging between 1 and 6 years of ag $\mathrm{e}^{[36]}$. A physiological maturation process that may be influenced by different genetic, metabolic or toxic factors has been proposed to explain its presence in both control and diseased children ${ }^{[35]}$. These lesions usually show net margins on $\mathrm{T} 2$ weighted images, involve the dorsal para-central portions on axial planes and the pons and midbrain in a preferential manner (Figure 3).

In summary, the discrepancy between neuropathology reports, experimental studies in animals and clinical observations has generated a debate on the role of brainstem lesions in HIE. In fact, the severity of hypoxic-ischemic injury is an important issue to consider when interpreting results from autopsy studies and comparing them to clinical studies that are conducted on neonates who survived to HIE; also, the pathologic conditions and related events that lead to HIE in neonates are complex and very difficult to replicate in the experimental design of animal studies. Nevertheless, neonates with HIE and isolated brainstem lesions (in the absence of detectable supratentorial injury) suggest that a "brainstem watershed pattern" of brain HIE-related injury might exist, although rare in prevalence ${ }^{[15]}$.

\section{Clinico-radiological correlation and outcome}

Tegmental lesions of the brainstem involve several structures that are crucial for vital functions: The tegmentum of the medulla oblongata includes the XII nerve nucleus, dorsal nucleus of the $X$ cranial nerve, nucleus ambiguus, gracile nucleus of Goll, cuneate nucleus of Burdach, spinal nucleus of the trigeminal nerve, reticular formation, solitary tract and the preBotzinger complex, crucial for the stereotyped sequence of feeding and respiration ${ }^{[37]}$; the tegmentum of the pons includes the VII and VI cranial nerve nucleus, spinal nucleus, main sensory nucleus and mesencephalic nucleus of the $\mathrm{V}$ cranial nerve and reticular formation; the tegmentum of the midbrain includes the central nucleus of the inferior colliculus, the III and IV cranial nerve nucleus, the mesencephalic nucleus of the $\mathrm{V}$ cranial nerve, locus coeruleus, and reticular formation.

In the clinical scenario of total asphyxia the involvement of the brainstem in neonates has been associated with oculomotor disturbances, bilateral facial nerve palsy, ventilatory disturbances, and impaired sucking and swallowing ${ }^{[8,15]}$. These patients also show hypotonia, spastic tetraplegia, seizures, and psychomotor delay in different combinations and carry a high risk of postnatal mortality $^{[15]}$. Association studies do not demonstrate causality, especially in the case of respiratory and swallowing alterations that are finely modulated by the functional and structural connectivity between the brainstem, suprabulbar cortex and basal ganglia. Nevertheless, the central pattern generators of these functions are located in the brainstem ${ }^{[37]}$ and their damage needs to be considered in neonates and infants with HIE.

A preferential involvement of the brainstem with 

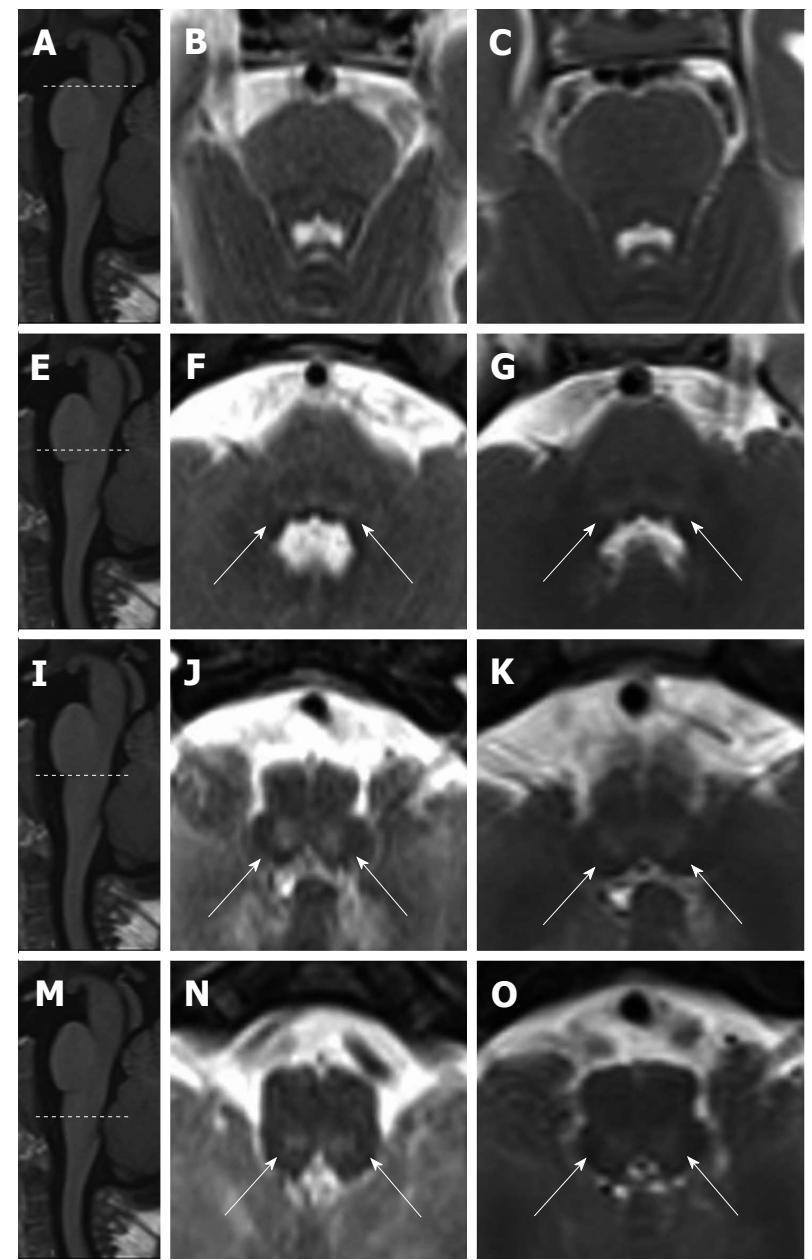
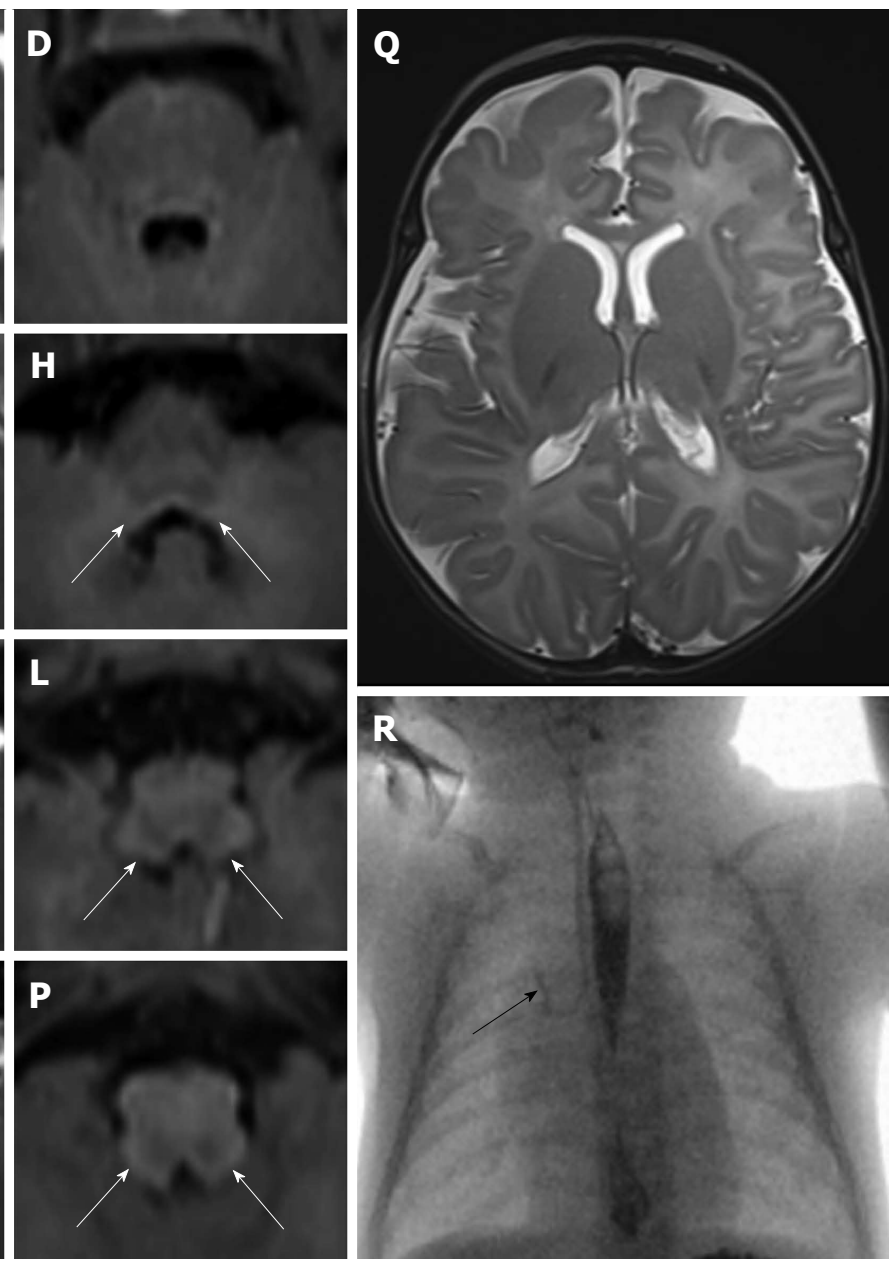

Figure 2 Brainstem tegmental lesions and oral motor dysfunction. An infant with perinatal asphyxia due to knotting of umbilical cord around the neck is shown. Apgar score at five minutes after birth. Eighteen days after birth (panels B, F, J and N), MR images show faint T2 hyperintense (white arrows in $F, J$, and N) bilateral and symmetric tegmental lesions of the caudal pons and medulla oblongata. Forty days after birth (panels C, D, G, H, K, L, O and P), MR images confirm T2 hyperintense (white arrows in $\mathrm{G}, \mathrm{K}$, and $\mathrm{O}$ ) and $\mathrm{T} 1$ hypointense (white arrows in $\mathrm{H}, \mathrm{L}$, and $\mathrm{P}$ ) bilateral and symmetric tegmental lesions of the caudal pons and medulla oblongata. No signal alterations are detected at the level of the cranial pons (B-D) and at supratentorial level (Q). At $1 \mathrm{mo}$, an upper GI tract X-ray showed iodinated contrast (Iopamidol, IOPAMIRO 300) inhalation (black arrow in panel R points to the right bronchus). Gastrostomy was performed. At the age of 2 years, psychomotor delay and dysphagia are present. Sagittal views of the brainstem (panels A, E, I and M) are used for reference of axial images. MR: Magnetic resonance.

specific involvement of the facial and abducens nuclei has been known as Möbius syndrome. A spectrum of symptoms caused by lesions located rostral and caudal to these nuclei may be associated with other oculomotor nerve nuclei and with dysphagia-gastroesophageal reflux complex ${ }^{[15,29]}$. Heterogeneity of clinical presentation, outcome $^{[38]}$ and genetic loci involved in Möbius syndrome ${ }^{[39,40]}$ led to propose a syndromic spectrum that may also include the rarely reported cases of neonates with a history of HIE or perinatal sentinel events of $\mathrm{HIE}^{[41]}$, who present tegmental lesions without supratentorial involvement at MR imaging ${ }^{[15,29]}$. A recent systematic review conducted on the literature published between 1980 and 2011 has shown that there is currently limited evidence on the relationship of early sucking and swallowing problems in neonatal brain injury with patterns of neonatal brain injury ${ }^{[42]}$. Early sucking and swallowing problems were reported to be present in 35\% to $48 \%$ of infants with different types of neonatal brain injury. However, data from the few available relevant studies were shown to be heterogeneous in terms of the research design, levels of evidence (levels II, III and IV), infant populations described, and assessment measures used $^{[42]}$.

When lesions in the brainstem are diagnosed with basal ganglia-thalamus and/or cortex lesions, the outcome is often dismal and brainstem injury is the most powerful predictor of death ${ }^{[43,44]}$ in children with $\mathrm{HIE}$, with up to $50 \%$ of children dying in the neonatal period or during infancy ${ }^{[45]}$. Among survivors to $\mathrm{HIE}$, the most frequent clinical complaints that may be predicted by brainstem lesions include feeding problems, speech, language and communication problems and visual impairments. Prediction of these symptoms is crucial to appropriately plan the short and long term care of an infant who has suffered with HIE and counsel the parents for a better neurocognitive development and outcome ${ }^{[4]]}$.

Feeding problems can range from some difficulties with swallowing solids or liquids to being unable to 

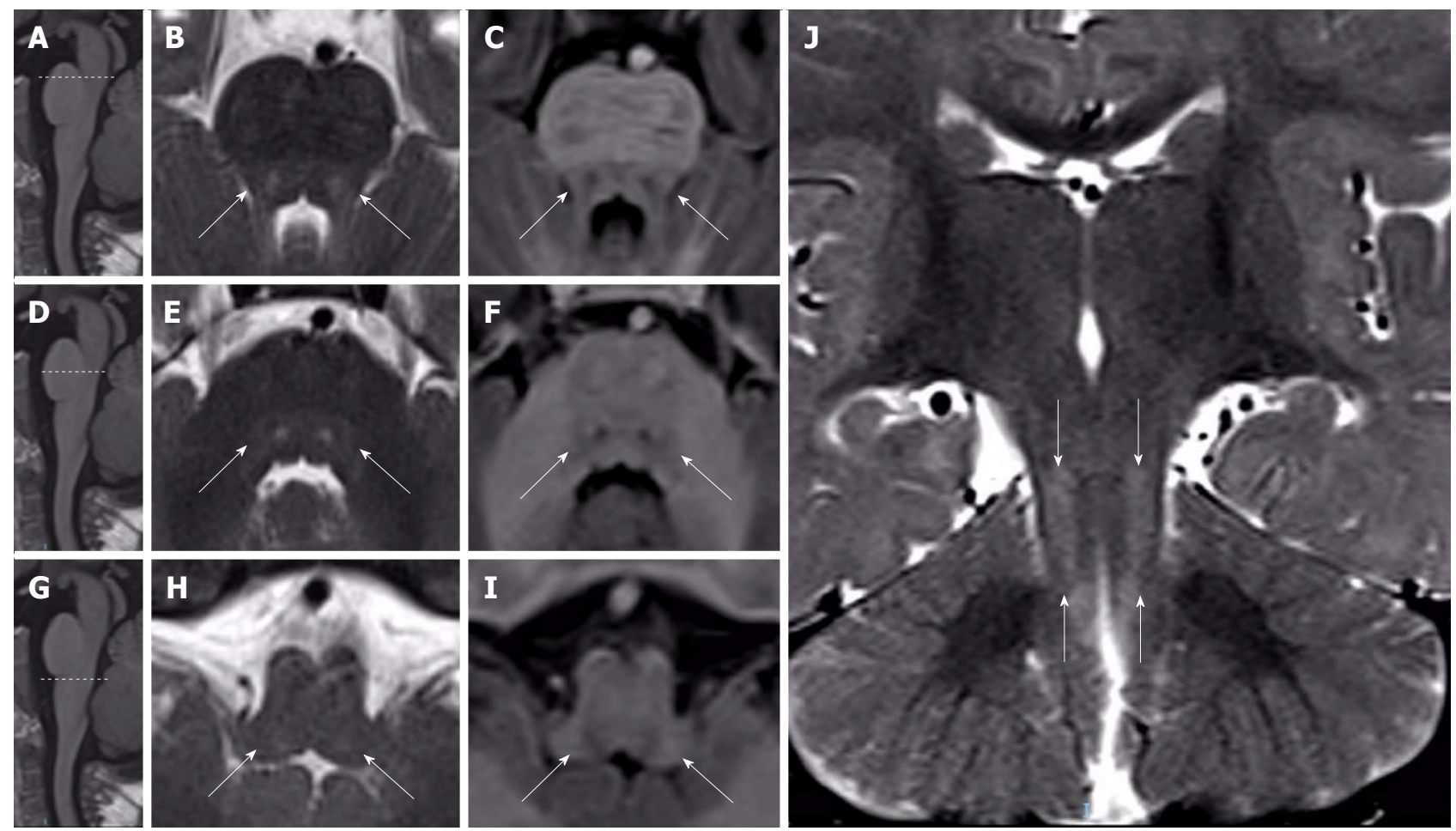

Figure 3 Brainstem tegmental lesions of the central tegmental tracts. A 1-year-old infant shows generalized hypotonia, macrocephaly and psycho-motor developmental delay, without a history of hypoxic-ischemic encephalopathy or adverse perinatal events. A genetic syndrome is suspected and is currently not known. MR images show isolated T2 hyperintense (white arrows in B, E, and H) and T1 hypointense (white arrows in C, F, and I) bilateral and symmetric tegmental lesions of the pons and caudal midbrain. Faint T2 hyperintense signal is observed at the rostral medulla oblongata. Columnar shape of alterations is demonstrated in coronal T2 weighted images $(\mathrm{J})$. No signal alterations are detected at the supratentorial level $(\mathrm{J})$. Sagittal views of the brainstem $(A, D$, and $G)$ are used for reference of axial images. MR: Magnetic resonance.

feed orally with the need for long-term gavage feeding. When gavage feeding is necessary, almost all neonates show involvement of the brainstem ${ }^{[15,45]}$. Logistic regression analyses have shown that only the severity of basal ganglia-thalamus and mesencephalic injury are independently associated with feeding impairment and that only the severity of basal ganglia-thalamus injury and pontine involvement are independently associated with gastrostomy insertion ${ }^{[45]}$.

These data show that assessment of the brainstem on neonatal MRI may provide important prognostic information about the severity of feeding impairments in survivors to neonatal HIE.

Despite their impact on children quality of life and prevention of malnutrition and other complications, gavage feeding and gastrostomy are procedures that are not easily accepted by parents. Thus, early identification of infants likely to need these procedures, allows early implementation of strategies in the care of children and their families ${ }^{[45]}$.

\section{Future perspectives}

The current knowledge on the so-called "dorsal brainstem syndrome" is limited, mainly due to the relative low frequency of isolated brainstem involvement in neonates with $\mathrm{HIE}$, which remains an exceptional event. However, timing of scans, high quality neonatal MRI and radiologist awareness are necessary pre-requisites to identify brainstem lesions. Also the wide range of differential diagnoses for T2 hyperintense tegmental lesions requires careful analysis of images and often second opinion for a correct interpretation. Prospective multicenter studies should be designed to conduct analyses on larger and homogeneous populations of neonates and infants. Such studies will help to identify vulnerable children carrying susceptibility genes, to find mechanisms of early vulnerability of the brainstem to hypoxic-ischemic damage and to predict motor and/or neurocognitive outcomes.

\section{REFERENCES}

1 Douglas-Escobar M, Weiss MD. Hypoxic-ischemic encephalopathy: a review for the clinician. JAMA Pediatr 2015; 169: 397-403 [PMID: 25685948]

2 Volpe JJ. Brain injury in premature infants: a complex amalgam of destructive and developmental disturbances. Lancet Neurol 2009; 8: 110-124 [PMID: 19081519 DOI: 10.1016/S1474-4422(08)70294-1]

3 Jacobs SE, Berg M, Hunt R, Tarnow-Mordi WO, Inder TE, Davis PG. Cooling for newborns with hypoxic ischaemic encephalopathy. Cochrane Database Syst Rev 2013; 1: CD003311 [PMID: 23440789 DOI: 10.1002/14651858.CD003311]

4 Azzopardi D, Strohm B, Marlow N, Brocklehurst P, Deierl A, Eddama O, Goodwin J, Halliday HL, Juszczak E, Kapellou O, Levene M, Linsell L, Omar O, Thoresen M, Tusor N, Whitelaw A, Edwards AD. Effects of hypothermia for perinatal asphyxia on childhood outcomes. $N$ Engl J Med 2014; 371: 140-149 [PMID: 25006720 DOI: 10.1056/NEJMoa1315788]

5 Estan J, Hope P. Unilateral neonatal cerebral infarction in full 
term infants. Arch Dis Child Fetal Neonatal Ed 1997; 76: F88-F93 [PMID: 9135286]

6 Pierrat V, Haouari N, Liska A, Thomas D, Subtil D, Truffert P. Prevalence, causes, and outcome at 2 years of age of newborn encephalopathy: population based study. Arch Dis Child Fetal Neonatal Ed 2005; 90: F257-F261 [PMID: 15846019]

7 Counsell SJ, Tranter SL, Rutherford MA. Magnetic resonance imaging of brain injury in the high-risk term infant. Semin Perinatol 2010; 34: 67-78 [PMID: 20109974 DOI: 10.1053/ j.semperi.2009.10.007]

8 Ghei SK, Zan E, Nathan JE, Choudhri A, Tekes A, Huisman TA, Izbudak I. MR imaging of hypoxic-ischemic injury in term neonates: pearls and pitfalls. Radiographics 2014; 34: 1047-1061 [PMID: 25019441 DOI: 10.1148/rg.344130080]

9 Quattrocchi CC, Longo D, Delfino LN, Errante Y, Aiello C, Fariello G, Bernardi B. MR differential diagnosis of acute deep grey matter pathology in paediatric patients. Pediatr Radiol 2013; 43: 743-761 [PMID: 23196927 DOI: 10.1007/s00247-012-2491-2]

10 Voit T, Lemburg P, Neuen E, Lumenta C, Stork W. Damage of thalamus and basal ganglia in asphyxiated full-term neonates. Neuropediatrics 1987; 18: 176-181 [PMID: 3317104]

11 Pasternak JF, Predey TA, Mikhael MA. Neonatal asphyxia: vulnerability of basal ganglia, thalamus, and brainstem. Pediatr Neurol 1991; 7: 147-149 [PMID: 2059257]

12 Barkovich AJ. MR and CT evaluation of profound neonatal and infantile asphyxia. AJNR Am J Neuroradiol 1992; 13: 959-972; discussion 973-975 [PMID: 1590198]

13 Barkovich AJ, Westmark K, Partridge C, Sola A, Ferriero DM. Perinatal asphyxia: MR findings in the first 10 days. AJNR Am J Neuroradiol 1995; 16: 427-438 [PMID: 7793360]

14 Sugama S, Eto Y. Brainstem lesions in children with perinatal brain injury. Pediatr Neurol 2003; 28: 212-215 [PMID: 12770675]

15 Quattrocchi CC, Longo D, Delfino LN, Cilio MR, Piersigilli F, Capua MD, Seganti G, Danhaive O, Fariello G. Dorsal brain stem syndrome: MR imaging location of brain stem tegmental lesions in neonates with oral motor dysfunction. AJNR Am J Neuroradiol 2010; 31: 1438-1442 [PMID: 20395394 DOI: 10.3174/ajnr.A2103]

16 Alderliesten T, Nikkels PG, Benders MJ, de Vries LS, Groenendaal F. Antemortem cranial MRI compared with postmortem histopathologic examination of the brain in term infants with neonatal encephalopathy following perinatal asphyxia. Arch Dis Child Fetal Neonatal Ed 2013; 98: F304-F309 [PMID: 23172767 DOI: 10.1136/archdischild-2012-301768]

17 Berbaum KS, Franken EA, Dorfman DD, Rooholamini SA, Kathol MH, Barloon TJ, Behlke FM, Sato Y, Lu CH, el-Khoury GY. Satisfaction of search in diagnostic radiology. Invest Radiol 1990; 25: 133-140 [PMID: 2312249]

18 Gilles FH. Hypotensive brain stem necrosis. Selective symmetrical necrosis of tegmental neuronal aggregates following cardiac arrest. Arch Pathol 1969; 88: 32-41 [PMID: 5793687]

19 Schneider H, Ballowitz L, Schachinger H, Hanefeld F, Dröszus JU. Anoxic encephalopathy with predominant involvement of basal ganglia, brain stem and spinal cord in the perinatal period. Report on seven newborns. Acta Neuropathol 1975; 32: 287-298 [PMID: 1180007]

20 Leech RW, Alvord EC. Anoxic-ischemic encephalopathy in the human neonatal period. The significance of brain stem involvement. Arch Neurol 1977; 34: 109-113 [PMID: 836361]

21 Shioda M, Hayashi M, Takanashi J, Osawa M. Lesions in the central tegmental tract in autopsy cases of developmental brain disorders. Brain Dev 2011; 33: 541-547 [PMID: 20970935 DOI: 10.1016/j.braindev.2010.09.010]

22 Goyal M, Versnick E, Tuite P, Cyr JS, Kucharczyk W, Montanera W, Willinsky R, Mikulis D. Hypertrophic olivary degeneration: metaanalysis of the temporal evolution of MR findings. AJNR Am $J$ Neuroradiol 2000; 21: 1073-1077 [PMID: 10871017]

23 Sarnat HB. Watershed infarcts in the fetal and neonatal brainstem. An aetiology of central hypoventilation, dysphagia, Möibius syndrome and micrognathia. Eur J Paediatr Neurol 2004; 8: 71-87 [PMID: 15253055]
24 Leong S, Ashwell KW. Is there a zone of vascular vulnerability in the fetal brain stem? Neurotoxicol Teratol 1997; 19: 265-275 [PMID: 9253005]

25 Jensen A, Garnier Y, Berger R. Dynamics of fetal circulatory responses to hypoxia and asphyxia. Eur J Obstet Gynecol Reprod Biol 1999; 84: 155-172 [PMID: 10428339]

26 Myers RE. Two patterns of perinatal brain damage and their conditions of occurrence. Am J Obstet Gynecol 1972; 112: 246-276 [PMID: 4621486]

27 Sugama S, Ariga M, Hoashi E, Eto Y. Brainstem cranial-nerve lesions in an infant with hypoxic cerebral injury. Pediatr Neurol 2003; 29: 256-259 [PMID: 14629914]

28 Saito Y, Kawashima Y, Kondo A, Chikumaru Y, Matsui A, Nagata I, Ohno K. Dysphagia-gastroesophageal reflux complex: complications due to dysfunction of solitary tract nucleus-mediated vago-vagal reflex. Neuropediatrics 2006; 37: 115-120 [PMID: 16967360]

29 Hiyane M, Saito Y, Saito T, Komaki H, Nakagawa E, Sugai K, Sasaki M, Sato N, Yamamoto T, Imai Y. A case of bulbar type cerebral palsy: representative symptoms of dorsal brainstem syndrome. Brain Dev 2012; 34: 787-791 [PMID: 22306266 DOI: 10.1016/j.braindev.2012.01.003]

30 van der Knaap MS, Barth PG, Gabreëls FJ, Franzoni E, Begeer JH, Stroink H, Rotteveel JJ, Valk J. A new leukoencephalopathy with vanishing white matter. Neurology 1997; 48: 845-855 [PMID: 9109866]

31 Tada H, Takanashi J, Barkovich AJ, Yamamoto S, Kohno Y. Reversible white matter lesion in methionine adenosyltransferase I/III deficiency. AJNR Am J Neuroradiol 2004; 25: 1843-1845 [PMID: 15569761]

32 Takanashi J, Kanazawa M, Kohno Y. Central tegmental tract involvement in an infant with 6-pyruvoyltetrahydropterin synthetase deficiency. AJNR Am J Neuroradiol 2006; 27: 584-585 [PMID: 16551996]

33 Khong PL, Lam BC, Chung BH, Wong KY, Ooi GC. Diffusionweighted MR imaging in neonatal nonketotic hyperglycinemia. AJNR Am J Neuroradiol 2003; 24: 1181-1183 [PMID: 12812951]

34 Sakai Y, Kira R, Torisu H, Ihara K, Yoshiura T, Hara T. Persistent diffusion abnormalities in the brain stem of three children with mitochondrial diseases. AJNR Am J Neuroradiol 2006; 27: 1924-1926 [PMID: 17032867]

35 Aguilera-Albesa S, Poretti A, Honnef D, Aktas M, Yoldi-Petri ME, Huisman TA, Häusler M. T2 hyperintense signal of the central tegmental tracts in children: disease or normal maturational process? Neuroradiology 2012; 54: 863-871 [PMID: 22271318 DOI: $10.1007 / \mathrm{s} 00234-012-1006-\mathrm{z}]$

36 Yoshida S, Hayakawa K, Yamamoto A, Aida N, Okano S, Matsushita H, Kanda T, Yamori Y, Yoshida N, Hirota H. Symmetrical central tegmental tract (CTT) hyperintense lesions on magnetic resonance imaging in children. Eur Radiol 2009; 19: $462-469$ [PMID: 18795297 DOI: $10.1007 / \mathrm{s} 00330-008-1167-7]$

37 Jean A. Brain stem control of swallowing: neuronal network and cellular mechanisms. Physiol Rev 2001; 81: 929-969 [PMID: 11274347]

38 Matsui K, Kataoka A, Yamamoto A, Tanoue K, Kurosawa K, Shibasaki J, Ohyama M, Aida N. Clinical characteristics and outcomes of Möbius syndrome in a children's hospital. Pediatr Neurol 2014; 51: 781-789 [PMID: 25306435 DOI: 10.1016/j.pedia trneurol.2014.08.011]

39 MacKinnon S, Oystreck DT, Andrews C, Chan WM, Hunter DG, Engle EC. Diagnostic distinctions and genetic analysis of patients diagnosed with moebius syndrome. Ophthalmology 2014; 121: 1461-1468 [PMID: 24612975 DOI: 10.1016/j.ophtha.2014.01.006]

40 Tomas-Roca L, Tsaalbi-Shtylik A, Jansen JG, Singh MK, Epstein JA, Altunoglu U, Verzijl H, Soria L, van Beusekom E, Roscioli T, Iqbal Z, Gilissen C, Hoischen A, de Brouwer AP, Erasmus C, Schubert D, Brunner H, Pérez Aytés A, Marin F, Aroca P, Kayserili H, Carta A, de Wind N, Padberg GW, van Bokhoven H. De novo mutations in PLXND1 and REV3L cause Möbius syndrome. Nat Commun 2015; 6: 7199 [PMID: 26068067 DOI: 10.1038/ 
ncomms8199]

41 Martinez-Biarge M, Madero R, González A, Quero J, GarcíaAlix A. Perinatal morbidity and risk of hypoxic-ischemic encephalopathy associated with intrapartum sentinel events. $\mathrm{Am} J$ Obstet Gynecol 2012; 206: 148.e1-148.e7 [PMID: 22079054 DOI: 10.1016/j.ajog.2011.09.031]

42 Slattery J, Morgan A, Douglas J. Early sucking and swallowing problems as predictors of neurodevelopmental outcome in children with neonatal brain injury: a systematic review. Dev Med Child Neurol 2012; 54: 796-806 [PMID: 22607330 DOI: 10.1111/ j.1469-8749.2012.04318.x]

43 Martinez-Biarge M, Diez-Sebastian J, Kapellou O, Gindner D, Allsop JM, Rutherford MA, Cowan FM. Predicting motor outcome and death in term hypoxic-ischemic encephalopathy. Neurology 2011; 76: 2055-2061 [PMID: 21670434 DOI: 10.1212/ WNL.0b013e31821f442d]

44 Logitharajah P, Rutherford MA, Cowan FM. Hypoxic-ischemic encephalopathy in preterm infants: antecedent factors, brain imaging, and outcome. Pediatr Res 2009; 66: 222-229 [PMID: 19390490 DOI: 10.1203/PDR.0b013e3181a9ef34]

45 Martinez-Biarge M, Diez-Sebastian J, Wusthoff CJ, Lawrence S, Aloysius A, Rutherford MA, Cowan FM. Feeding and communication impairments in infants with central grey matter lesions following perinatal hypoxic-ischaemic injury. Eur J Paediatr Neurol 2012; 16: 688-696 [PMID: 22658307 DOI: 10.1016/j. ejpn.2012.05.001]

P- Reviewer: Gao BL, Nouh MR, Razek AA, Storto G S- Editor: Qiu S L- Editor: Wang TQ E- Editor: Liu SQ 


\section{DS \\ Baishideng ${ }^{\circledR}$}

Published by Baishideng Publishing Group Inc

8226 Regency Drive, Pleasanton, CA 94588, USA

Telephone: +1-925-223-8242

Fax: +1-925-223-8243

E-mail: bpgoffice@wignet.com

Help Desk: http://www.wjgnet.com/esps/helpdesk.aspx

http://www.wjgnet.com

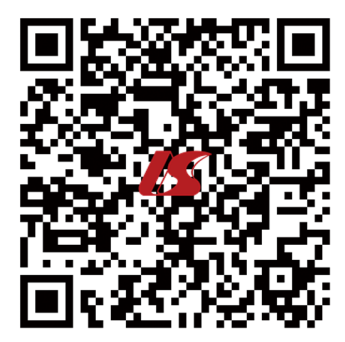

